\title{
BMJ Open Effectiveness and safety of oral sedation in adult patients undergoing dental procedures: a systematic review
}

\author{
Jimmy de Oliveira Araújo, ${ }^{1}$ Cristiane de Cássia Bergamaschi (iD ,2 \\ Luciane Cruz Lopes (1) ,2 Caio Chaves Guimarães (1) ,' Natalia Karol de Andrade, ${ }^{1}$ \\ Juliana Cama Ramacciato, ${ }^{1}$ Rogério Heládio Lopes Motta (iD ${ }^{1}$
}

To cite: Araújo Jd0,

Bergamaschi CdC, Lopes LC, et al. Effectiveness and safety of oral sedation in adult patients undergoing dental procedures: a systematic review. BMJ Open 2021;11:e043363. doi:10.1136/ bmjopen-2020-043363

- Prepublication history and additional material for this paper are available online. To view these files, please visit the journal online (http://dx.doi. org/10.1136/bmjopen-2020043363).

Received 02 August 2020 Revised 30 November 2020 Accepted 31 December 2020

Check for updates

(c) Author(s) (or their employer(s)) 2021. Re-use permitted under CC BY-NC. No commercial re-use. See rights and permissions. Published by BMJ.

${ }^{1}$ Division of Pharmacology, Anesthesiology and

Therapeutics, Faculdade São Leopoldo Mandic, Instituto de Pesquisas São Leopoldo Mandic, Campinas, Brazil

${ }^{2}$ Department of Pharmaceutical Sciences, Universidade da Sorocaba, Sorocaba, Brazil

Correspondence to Professor Rogério Heládio Lopes Motta;

rogerio.motta@sImandic.edu.br

\section{ABSTRACT}

Objectives It can be challenging to manage patients who are anxious during dental procedures. There is a lack of evidence regarding the effectiveness and safety of oral sedation in adults. This study evaluated the effectiveness and safety of oral sedation in patients undergoing dental procedures.

Design Systematic review.

Methods Randomised clinical trials (RCTs) compared the oral use of benzodiazepines and other medications with a placebo or other oral agents in adult patients. A search of the Cochrane (CENTRAL), MEDLINE (via Ovid), EMBASE (via Ovid) and Cumulative Index to Nursing and Allied Health Literature (via Ovid) databases was conducted, without any restrictions on language or date of publication. The primary outcomes included the adverse effects and anxiety level. The secondary outcomes included sedation, satisfaction with the treatment, heart rate, respiratory rate, blood pressure and oxygen saturation. Reviewers, independently and in pairs, assessed each citation for eligibility, performed the data extraction and assessed the risk of bias. A narrative synthesis of the data was provided. Results A number of RCTs ( $n=327$ patients) assessed the use of benzodiazepines $(n=9)$ and herbal medicines $(n=3)$. We found good satisfaction with treatment after the use of midazolam $7.5 \mathrm{mg}$ or clonidine $150 \mu \mathrm{g}$ and reduced anxiety with alprazolam ( 0.5 and $0.75 \mathrm{mg}$ ). Midazolam 15 $\mathrm{mg}$ promoted greater anxiety reduction than Passiflora incarnata L. $260 \mathrm{mg}$, while Valeriana officinalis $100 \mathrm{mg}$ and Erythrina mulungu $500 \mathrm{mg}$ were more effective than a placebo. More patients reported adverse effects with midazolam $15 \mathrm{mg}$. Diazepam $15 \mathrm{mg}$ and V. officinalis 100 mg promoted less change in the heart rate and blood pressure than a placebo.

Conclusions Given the limitations of the findings due to the quality of the included studies and the different comparisons made between interventions, further RCTs are required to confirm the effectiveness and safety of oral sedation in dentistry.

PROSPERO registration number CRD42017057142.

\section{INTRODUCTION}

Anxiety during dental treatment can cause stress and discomfort in patients and lead to dental treatment avoidance with consequent damage to the oral health of phobic
Strengths and limitations of this study

- We performed a comprehensive systematic review to identify randomised clinical trials that evaluated the effectiveness and safety of oral sedation in patients undergoing dental surgical procedures.

- Anxiety can lead to dental treatment avoidance with consequent exacerbation of poor oral health in phobic patients; therefore, it is important to understand which drugs are effective for anxiety control, as this can contribute to patient compliance to dental treatment.

- Adverse effects from oral sedatives are negative outcomes in dentistry that should be avoided; therefore, it is important that we estimate the risk of such effects so that decision-making regarding conscious sedation can be better informed.

- This study was carried out with methodological rigour, including explicit eligibility criteria, a broad extensive database search, study selection by reviewers working in pairs and independently and evaluation of the risk of bias.

- The quality of the included studies and different comparisons made between interventions were limiting factors for the study findings.

patients. ${ }^{12}$ In this context, effective control of anxiety plays a pivotal role in patient compliance to dental treatment. The use of conscious sedation is an important strategy for the behavioural management of patients who suffer from anxiety over dental treatment. ${ }^{3}$ Conscious sedation is an approach that uses one or more drugs to produce a state of central nervous system depression while maintaining verbal contact with the patient throughout the procedure. ${ }^{4}$ The sedation level should be such that the patient remains conscious and can readily understand and respond to verbal instructions or tactile stimulation. ${ }^{5}$

Indications for the use of conscious sedation include a diagnosis of anxiety and dental phobia, prolonged or traumatic dental 
procedures and medical conditions potentially aggravated by stress, which can reduce the patient's ability to cooperate. $^{6}$

Additionally, the release of endogenous catecholamines can increase the cardiovascular system load in patients with a history of angina, whereas asthmatic patients can present stress-induced acute episodes of breathing difficulty induced by stress. These are among some of the patients' profiles that can benefit from conscious sedation in reducing exacerbation risk. The risk-benefit should be determined according to the severity of the patient's condition. $^{7}$

Oral sedation is one of the relatively accessible means for dental professionals to control patient anxiety. However, oral sedation can have inherent limitations due to the pharmacokinetics of the orally administered drug, such as delayed and variable onsets of action. ${ }^{8}$ Moreover, drug interventions to provide conscious sedation should have a sufficient safety margin to preclude consciousness loss. ${ }^{9}$

Benzodiazepines are widely used in oral sedation to induce a state of anxiety in dental procedures. ${ }^{10}$ These drugs are among the most commonly prescribed and employed for this purpose worldwide. ${ }^{581112}$

Although benzodiazepines have a similar mechanism of action, their pharmacokinetics differ, which are key factors in selecting the best option to suit the patient. ${ }^{13}$ The different oral sedation options in dentistry include midazolam, diazepam and lorazepam as mainstream drugs, although alprazolam, temazepam and oxazepam have also been used. ${ }^{8}$

Few studies have synthesised the available evidence on the effectiveness and safety of oral sedation in adults undergoing dental procedures. A systematic review evaluated the safety of using drugs for sedation administered by oral, intranasal, sublingual, intramuscular and intravenous routes in adults undergoing dental procedures. However, the data extraction was not performed in pairs and independently, and the risk of bias or quality of the evidence was not assessed. ${ }^{10}$ Another systematic review investigated the use of midazolam in dental surgical procedures. Of the ten studies included in the review, only three addressed oral use, while the other studies combined drugs administered orally and via other routes. ${ }^{14}$

The hypothesis of this study was that conscious oral sedation is effective and safe for use in dental procedures. The gap in knowledge on the use of drugs for oral sedation in dentistry prompted this systematic review to determine the effectiveness and safety of oral sedation drugs in adult patients undergoing dental surgical procedures.

\section{METHODS}

\section{Protocol registration}

The protocol of this systematic review was registered on the PROSPERO-International Prospective Register of Systematic Reviews and also published. ${ }^{15}$

The population, intervention, comparator and outcomes strategy used was as follows: population, adults requiring dental surgical procedures; intervention, oral sedation; comparator, placebo group or other oral drug administered; and outcomes, effectiveness: anxiety, sedation and satisfaction with the treatment and safety: adverse effect, heart rate, respiratory rate, blood pressure and oxygen saturation.

\section{Patient and public involvement}

No patients were involved.

\section{Eligibility criteria of the studies}

Inclusion criteria

Participants

Adults requiring dental surgical procedures, such as dental extraction, surgery for orthodontic purposes, removal of residual roots and third molars, dental implants and other dental surgical interventions.

\section{Intervention}

At least one group used oral sedation with benzodiazepines or other drugs (eg, herbal medicines).

\section{Comparator}

Placebo group or other drug administered orally.

\section{Study}

Randomised clinical trials (RCTs).

\section{Exclusion criteria}

Studies involving adults with respiratory diseases, with contraindications to benzodiazepine; pregnant and/or breastfeeding women; and those with a history of allergies were not included. Studies that combined the administration of different drugs for oral sedation were also excluded.

\section{Outcomes assessed}

Primary outcomes

1. Effectiveness was measured by improvement in anxiety by using the Dental Anxiety Scale (DAS), Oral Surgery Confidence Questionnaire (OSCQ) and/or other scales for anxiety symptoms.

2. Safety was measured by the number of participants that reported side effects, number of adverse effects (or adverse drug reactions) and number of participants that dropped out due to side effects.

\section{Secondary outcomes}

1. Secondary outcomes of effectiveness were sedation and satisfaction with the treatment.

2. Secondary outcomes of safety were heart rate, respiratory rate, blood pressure and oxygen saturation.

\section{Search method for identifying studies}

Electronic database search

The following databases were searched: Cochrane Central Register of Controlled Trials (CENTRAL), which includes Dentistry and Oral Health Group's Specialized Register; MEDLINE (via Ovid); Excerpta Medica Database (EMBASE) (via Ovid); Cumulative Index to Nursing and 
Allied Health Literature (via Ovid), Lilacs (Scielo) and the Capes database (https://catalogodeteses.capes.gov. $\mathrm{br} /$ catalogo-teses/\#!/), without restrictions on language or publication date, with the search encompassing articles published between inception and 12 March 2020.

\section{Other reference search sources}

The reviewers (CCB and JOA) manually analysed the reference list or citations of the articles to retrieve and identify other possible eligible studies. The main authors and/or pharmaceutical companies involved in producing the drugs were contacted for information on additional trials, if necessary.

\section{Search strategy}

The search was conducted using Medical Subject Headings terms for each oral surgical procedure (such as oral surgery, dental extraction and dental implant), benzodiazepines (and its synonyms) and terms to search for other drugs. The search strategy for MEDLINE (via Ovid) was adapted for each database (online supplemental appendix A).

\section{Study records}

Data management

After performing the search strategies on each electronic database, the researchers imported the results from each search into an EndNote library. Duplicate entries were identified and removed.

\section{Study eligibility determination}

Relevant data from the eligible studies were independently extracted into Microsoft Excel, using a standardised data extraction form. Four reviewers (JOA and CCB, CCG and NKA), working in pairs and independently, selected potentially relevant titles and abstracts and applied the eligibility criteria. Full texts of the potentially eligible articles were obtained. Similarly, the reviewers checked the eligibility of each study. Disagreements were resolved by consensus and, when necessary, arbitrated by a third reviewer (RHLM or LCL).

\section{Data extraction}

The same reviewers (JOA and CCB, CCG and NKA), working in pairs and independently, used a standardised and pretested form for data extraction. Subsequently, the reviewers extracted the patient data, methods, interventions and outcomes. We contacted the authors for articles with incomplete methods and results data, if necessary. Disagreements were resolved by consensus and, when necessary, arbitrated by a third reviewer (RHLM or LCL).

\section{Risk of bias}

A modified version of the Cochrane collaboration approach for assessing the risk of bias was used. ${ }^{16} 17$ The same reviewers, again in pairs and independently, evaluated the risk of bias for each clinical trial according to randomisation; allocation concealment; blinding of patients, health professionals and outcome assessors; incomplete outcome data; selective outcome reporting; and major baseline imbalance characterising the sample.

The same reviewers attributed the standard answers 'definitely yes', 'probably yes', 'probably no' and 'definitely no' for each domain, with 'definitely yes' and 'probably yes' denoting a low risk of bias and 'definitely no' and 'probably no' attributing a high risk of bias. ${ }^{18}$ Disagreements were resolved by consensus and, when necessary, arbitrated by a third reviewer (RHLM or LCL).

\section{Data synthesis and analysis of the quality of evidence}

A narrative synthesis of the findings was carried out. The extracted data were summarised in the tables with the measures (mean, SD and absolute and relative frequency).

Heterogeneity was explained by drug doses (higher vs lower) with greater effect than expected at higher doses and treatment time (longer vs shorter) ${ }^{15}$ Due to the divergences between the drugs prescribed and the doses used and measured outcomes, a meta-analysis was not performed, and the Grading of Recommendations, Assessment, Development and Evaluation could not be produced. ${ }^{19} 20$

\section{RESULTS}

\section{Search strategy results}

A total of 3,669 publications were retrieved, of which 49 were included for full-text selection. After application of the eligibility criteria, 10 RCTs were included in the review (figure 1). The studies' characteristics are given in online supplemental appendix B, and the excluded studies are listed in online supplemental appendix C.

\section{Description of the studies included}

The 10 RCTs involved 327 patients (58\% women) undergoing oral surgery. Most of the RCTs evaluated the use of benzodiazepines $(n=9)$, and three studies assessed the use of herbal medicines for oral sedation. The majority of the studies were conducted by Brazilian researchers between

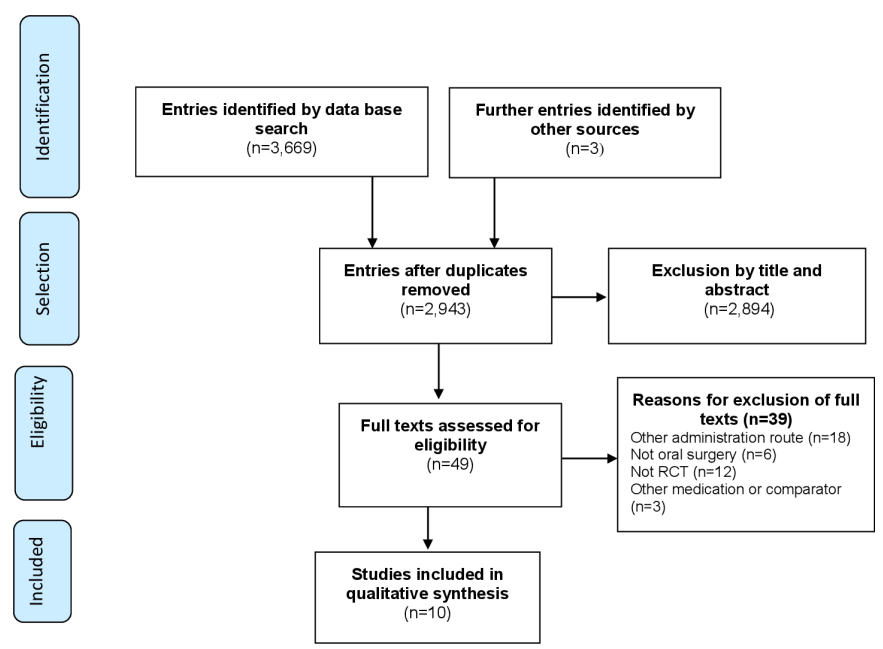

Figure 1 Flow chart of study selection process. RCT, randomised clinical trials. 
Table 1 Characteristics of the studies included ( $n=10$ studies)

\begin{tabular}{|c|c|c|}
\hline Variables & Studies (n) & Population (n) \\
\hline Study population & 10 & 327 \\
\hline Women $(n=282)$ & 8 & $164(58.2 \%)$ \\
\hline Alprazolam (0.25, 0.5 and $0.75 \mathrm{mg})$ & 1 & 36 \\
\hline Diazepam (5, 10 and 15 mg) & 3 & 49 \\
\hline Lorazepam (1 mg) & 1 & 10 \\
\hline \multicolumn{3}{|l|}{ Herbal medicines } \\
\hline Erythrina mulungu 500 mg & 1 & 30 \\
\hline Passiflora incarnata L. 260 mg & 1 & 40 \\
\hline Valeriana officinalis 100 mg & 1 & 10 \\
\hline \multicolumn{3}{|l|}{ Clinical condition } \\
\hline Dental implants & 2 & 45 \\
\hline Other dental surgery & 2 & 102 \\
\hline \multicolumn{3}{|l|}{ Country } \\
\hline Brazil & 5 & 135 \\
\hline USA & 1 & 48 \\
\hline Italy & 1 & 82 \\
\hline Switzerland & 1 & 12 \\
\hline China & 1 & 30 \\
\hline India & 1 & 20 \\
\hline Yes & 1 & 30 \\
\hline Not specified & 4 & 157 \\
\hline Not funded & 5 & 140 \\
\hline
\end{tabular}

2011 and 2017. Only one study was funded by the pharmaceutical industry (table 1).

\section{Risk of bias}

Random sequence generation

Some studies failed to report sufficient data on the randomisation process, precluding any assessment, and exhibited selection bias. $^{21-27}$ Some stated that patients were randomly allocated to groups but did not detail the process used (figure 2).

\section{Allocation concealment}

Some studies guaranteed that the random sequence generation of participants was unpredictable since the envelopes handed to participants were sealed and coded. $^{22} 2428$ By contrast, other clinical trials did not guarantee allocation concealment. ${ }^{2123252729}$ Two clinical trials provided insufficient information on the random sequence generation process employed. ${ }^{2630}$

\section{Blinding of the participants and personnel}

Rodrigo and Cheung ${ }^{22}$ and Coldwell et $a l^{23}$ clearly described that the blinding of participants and personnel was ensured and unlikely to have been lost and had no performance bias. The remaining studies stated that they were double-blinded but provided no further details. $^{21}$ 24-30 Consequently, these studies were deemed 'probably yes' and considered as having a low risk of bias.

\section{Blinding of the outcome assessors}

Blinding of the outcome assessors was performed in three studies, making it unlikely that blinding was lost. ${ }^{22} 2728$ Romano et $a l^{24}$ and Pinheiro et $a l^{30}$ stated that the professionals were blinded, but it was unclear whether they were 


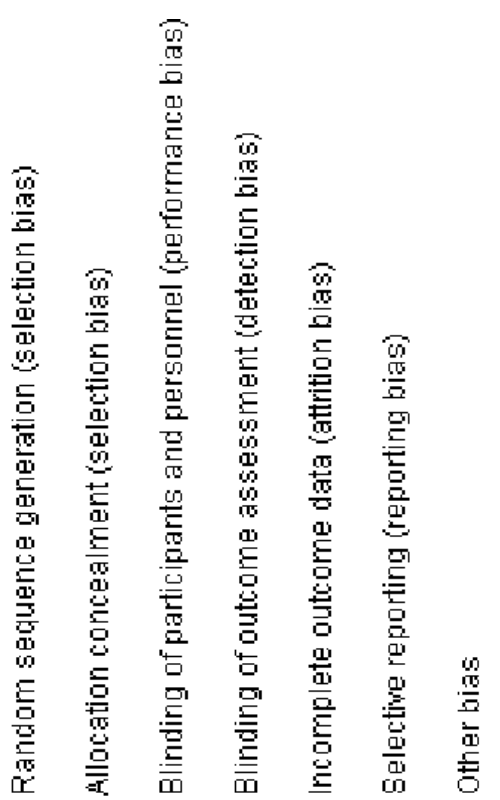

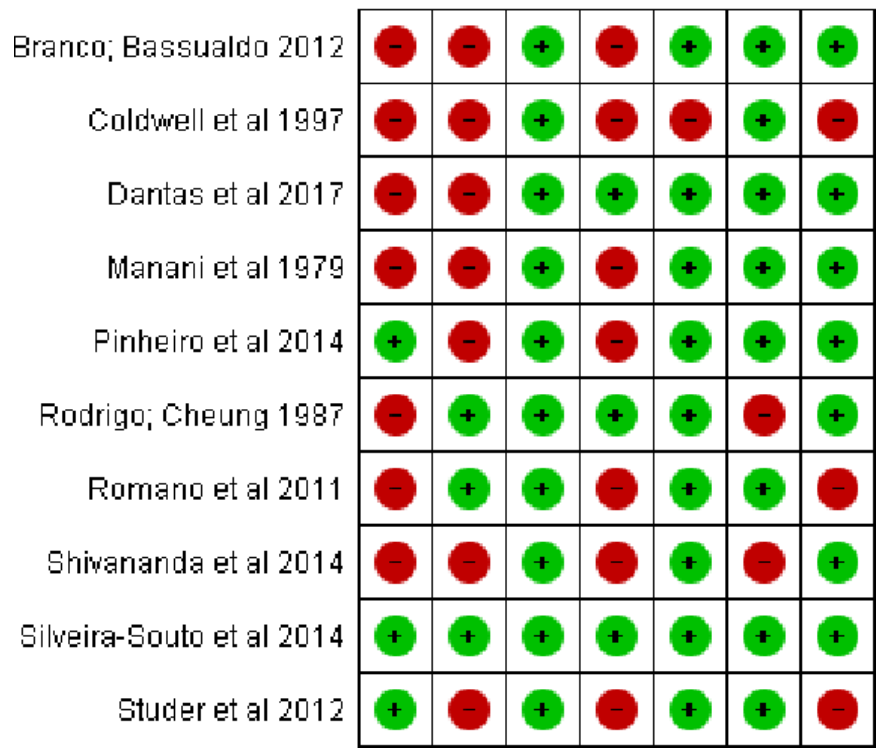

Figure 2 Consensus of the authors about bias risk for each study included.

blinded to the outcome collection. The other studies did not report this information, indicating detection bias. ${ }^{21} 23252629$

\section{Incomplete outcomes}

For the study by Coldwell $e t a l,{ }^{23}$ it was impossible to judge whether incomplete outcome reporting occurred. The remaining studies reported whether any participants were lost to follow-up or excluded for another reason.

\section{Selective outcome reporting}

One RCT recorded their protocol allowing confirmation that there was no selective outcome reporting. ${ }^{30}$ Although the study protocol was not reported for the other studies, it appears that they reported all the desired outcomes.

\section{Other sources of bias}

Only one study cited the source of funding. ${ }^{22}$ Other studies declared there was no funding. ${ }^{21} 2225-2830$ The remaining studies did not report sufficient information to assess the presence of other sources of bias. ${ }^{232429}$

\section{Outcomes assessed}

The primary and secondary outcomes reported by the studies are described in tables 2-4.

Due to differences between drugs used across groups, a meta-analysis of the data could not be performed, and the results were expressed in the form of a narrative synthesis. None of the studies reported sedation outcomes and respiratory rates.

Of the primary outcomes, five studies reported the anxiety levels, ${ }^{2325272830}$ and six studies collected information on the adverse effects. ${ }^{21-23} 272930$

Table 3 describes the studies that report the percentage of participants who experienced adverse effects. In general, most participants exhibited some adverse effects. Dantas $e t a l^{27}$ reported the number of adverse effects but did not report the number of patients with adverse effects. Coldwell $e t a l^{23}$ did not specify the adverse effect by group. Therefore, we did not include their results in the table.

The number of reports of adverse effects is shown in table 4. In general, a higher number of adverse effects was associated with the use of midazolam compared with $P$. incarnata and a placebo, where the most reported adverse effects were drowsiness, muscular relaxation and dizziness. ${ }^{22} 27$

The secondary outcomes reported were patient satisfaction with treatment $\left(\mathrm{n}=1\right.$ study), ${ }^{29}$ heart rate $(\mathrm{n}=5$ studies),,$^{2124272830}$ blood pressure $(n=5)^{2127-30}$ and oxygen saturation $(n=3) .{ }^{26} 28$

Reporting of the outcomes by drug Alprazolam (0.25, 0.5 and $0.75 \mathrm{mg})$

In a placebo-controlled RCT, 48 participants undergoing dental extraction were allocated into four groups ( $\mathrm{n}=12$ per group): group I, alprazolam $0.25 \mathrm{mg}$; group II, alprazolam $0.50 \mathrm{mg}$; group III, alprazolam $0.75 \mathrm{mg}$; and group IV, placebo. Anxiety was assessed using the DAS, OSCQ and the Interval Scale of Anxiety Response . The proportion of individuals that reported feeling fairly to very anxious during oral surgery decreased with increased doses of alprazolam. The most commonly observed adverse effect associated with the use of alprazolam at doses of $0.25,0.50$ and $0.75 \mathrm{mg}$ was anterograde amnesia. $^{23}$

\section{Diazepam (5, 10 and $15 \mathrm{mg})$ and lorazepam $(1 \mathrm{mg})$}

In a double-blind and placebo-controlled RCT, 30 participants undergoing dental implant placement surgery were allocated into three groups ( $\mathrm{n}=10$ per group). One hour before the procedure, they received the following interventions: group I, diazepam $10 \mathrm{mg}$; group II, lorazepam 1 mg; and group III, placebo. Anxiety was measured based on Corah's DAS. No significant difference was found between the groups concerning this outcome. ${ }^{25}$

An RCT allocated 82 patients undergoing outpatient dental surgery to group I, placebo; group II, trazodone 25 
Table 2 Primary and secondary outcomes reported by the studies $(n=9)$

\begin{tabular}{|c|c|c|c|c|c|c|}
\hline $\begin{array}{l}\text { Author (year) } \\
\text { (n=participants) }\end{array}$ & $\begin{array}{l}\text { Intervention group } \\
\text { (n=participants) }\end{array}$ & $\begin{array}{l}\text { Comparator group } \\
\text { (n=participants) }\end{array}$ & $\begin{array}{l}\text { *Primary } \\
\text { outcomes } \\
\text { (scales) }\end{array}$ & $\begin{array}{l}\text { Primary } \\
\text { outcome } \\
\text { results }\end{array}$ & $\begin{array}{l}\text { Secondary } \\
\text { outcomes }\end{array}$ & $\begin{array}{l}\text { Secondary } \\
\text { outcome } \\
\text { results }\end{array}$ \\
\hline $\begin{array}{l}\text { Coldwell et al } \\
1997^{23} \\
(n=48)\end{array}$ & $\begin{array}{l}\text { Alprazolam } 0.25 \\
\text { mg }(n=12) \\
\text { Alprazolam } 0.5 \text { mg } \\
(n=12) \\
\text { Alprazolam } 0.75 \\
\text { mg }(n=12)\end{array}$ & Placebo $(n=12)$ & $\begin{array}{l}\text { Anxiety } \\
(D A S, O S C Q \\
\text { and ISAR) }\end{array}$ & $\begin{array}{l}\text { Decrease } \\
\text { in number } \\
\text { of anxious } \\
\text { patients with } \\
\text { increasing } \\
\text { doses of } \\
\text { alprazolam }\end{array}$ & Not reported & \\
\hline $\begin{array}{l}\text { Branco, Bassualdo } \\
2012^{25} \\
(\mathrm{n}=30)\end{array}$ & $\begin{array}{l}\text { Diazepam } 10 \mathrm{mg} \\
(\mathrm{n}=10) \\
\text { Lorazepam } 1 \mathrm{mg} \\
(\mathrm{n}=10)\end{array}$ & Placebo $(n=10)$ & $\begin{array}{l}\text { Anxiety } \\
\text { (Corah's DAS) }\end{array}$ & $\begin{array}{l}\text { Decreased } \\
\text { anxiety } \\
\text { compared } \\
\text { with baseline } \\
\text { levels but } \\
\text { no statistical } \\
\text { difference } \\
\text { between } \\
\text { groups }\end{array}$ & Not reported & \\
\hline $\begin{array}{l}\text { Studer et al } 2012^{29} \\
\text { Crossover } \\
\text { (washout of } 30 \\
\text { days) } \\
(n=12)\end{array}$ & $\begin{array}{l}\text { Midazolam } 7.5 \mathrm{mg} \\
(\mathrm{n}=12)\end{array}$ & $\begin{array}{l}\text { Clonidine } 150 \mu \mathrm{g} \\
(\mathrm{n}=12)\end{array}$ & Not reported & & $\begin{array}{l}\text { Satisfaction with } \\
\text { the treatment } \\
\text { Blood pressure } \\
\text { (BP) }\end{array}$ & $\begin{array}{l}77 \% \text { of } \\
\text { patients } \\
\text { (midazolam } \\
\text { group) } \\
\text { versus } 75 \% \\
\text { (clonidine } \\
\text { group) } \\
\text { No statistical } \\
\text { difference } \\
\text { between the } \\
\text { groups for BP }\end{array}$ \\
\hline $\begin{array}{l}\text { Dantas et al } 2017^{27} \\
\text { Crossover } \\
\text { (washout of } 15-30 \\
\text { days) } \\
(n=40)\end{array}$ & $\begin{array}{l}\text { Passiflora incarnata } \\
\text { L. } 260 \mathrm{mg}(\mathrm{n}=40)\end{array}$ & $\begin{array}{l}\text { Midazolam } 15 \mathrm{mg} \\
(\mathrm{n}=40)\end{array}$ & $\begin{array}{l}\text { Anxiety } \\
\text { (Corah's DAS) }\end{array}$ & $\begin{array}{l}\text { Decreased } \\
\text { anxiety } \\
\text { compared } \\
\text { with baseline } \\
\text { levels but } \\
\text { no statistical } \\
\text { difference } \\
\text { between } \\
\text { groups }\end{array}$ & $\begin{array}{l}\text { Heart rate } \\
\text { Blood pressure } \\
\text { Oxygen } \\
\text { saturation }\end{array}$ & $\begin{array}{l}\text { No statistical } \\
\text { difference } \\
\text { between the } \\
\text { groups for } \\
\text { outcomes }\end{array}$ \\
\hline $\begin{array}{l}\text { Pinheiro et al } \\
2014^{30} \\
(\mathrm{n}=20)\end{array}$ & $\begin{array}{l}\text { Valeriana officinalis } \\
100 \mathrm{mg}(\mathrm{n}=10)\end{array}$ & $\begin{array}{l}\text { Placebo } \\
(n=10)\end{array}$ & $\begin{array}{l}\text { Anxiety } \\
(D A S)\end{array}$ & $\begin{array}{l}\text { Herbal } \\
\text { medicine was } \\
\text { more effective } \\
\text { than placebo }\end{array}$ & $\begin{array}{l}\text { Heart rate } \\
\text { Blood pressure }\end{array}$ & $\begin{array}{l}\text { No statistical } \\
\text { difference } \\
\text { between the } \\
\text { groups for } \\
\text { outcomes }\end{array}$ \\
\hline $\begin{array}{l}\text { Romano et al } \\
2011^{24} \\
(\mathrm{n}=40)\end{array}$ & $\begin{array}{l}\text { Midazolam } 15 \mathrm{mg} \\
(\mathrm{n}=20)\end{array}$ & Placebo $(n=20)$ & Not reported & & Heart rate & $\begin{array}{l}\text { No statistical } \\
\text { difference } \\
\text { between the } \\
\text { groups }\end{array}$ \\
\hline
\end{tabular}


Table 2 Continued

\begin{tabular}{|c|c|c|c|c|c|c|}
\hline $\begin{array}{l}\text { Author (year) } \\
\text { (n=participants) }\end{array}$ & $\begin{array}{l}\text { Intervention group } \\
\text { (n=participants) }\end{array}$ & $\begin{array}{l}\text { Comparator group } \\
\text { (n=participants) }\end{array}$ & $\begin{array}{l}\text { *Primary } \\
\text { outcomes } \\
\text { (scales) }\end{array}$ & $\begin{array}{l}\text { Primary } \\
\text { outcome } \\
\text { results }\end{array}$ & $\begin{array}{l}\text { Secondary } \\
\text { outcomes }\end{array}$ & $\begin{array}{l}\text { Secondary } \\
\text { outcome } \\
\text { results }\end{array}$ \\
\hline $\begin{array}{l}\text { Manani et al } 1979^{21} \\
(n=82)\end{array}$ & $\begin{array}{l}\text { Diazepam } 15 \mathrm{mg} \\
(\mathrm{n}=19) \\
\text { Trazodone } 25 \mathrm{mg} \\
(\mathrm{n}=20) \\
\text { Trazodone } 50 \mathrm{mg} \\
(\mathrm{n}=21)\end{array}$ & Placebo $(n=22)$ & Not reported & & $\begin{array}{l}\text { Heart rate } \\
\text { Blood pressure }\end{array}$ & $\begin{array}{l}\text { No statistical } \\
\text { difference } \\
\text { between the } \\
\text { groups }\end{array}$ \\
\hline $\begin{array}{l}\text { Shivananda et al } \\
2014^{26} \\
\text { Crossover }(n=20) \\
\text { (washout: not } \\
\text { reported) }\end{array}$ & $\begin{array}{l}\text { Diazepam } 5 \mathrm{mg} \\
(\mathrm{n}=20) \\
\text { Diazepam } 10 \mathrm{mg} \\
(\mathrm{n}=20)\end{array}$ & Placebo $(n=20)$ & Not reported & & $\begin{array}{l}\text { Oxygen } \\
\text { saturation }\end{array}$ & $\begin{array}{l}\text { No statistical } \\
\text { difference } \\
\text { between the } \\
\text { groups }\end{array}$ \\
\hline
\end{tabular}

Dental Anxiety Scale (DAS): categorises participants into not anxious, slightly anxious, fairly anxious and very anxious.

Oral Surgery Confidence Questionnaire (OSCQ): contains 11 items rated from 0, not at all confident, to 9, extremely confident.

Interval Scale of Anxiety Response (ISAR): contains a $90 \mathrm{~mm}$ vertical line labelled with descriptors alongside intervals determined according to estimated magnitude: 'calm, relaxed', 'a little nervous', 'tense, upset', 'afraid', 'very afraid', 'panicked' and 'terrified'.

Corah's Dental Anxiety Scale: contains four questions with five possible answers that assess the patient's feelings, signs and reactions related to the dental procedure, as very little anxious (up to five points), slightly anxious (6-10 points), moderately anxious (11-15 points) points and extremely anxious (16-20 points).

*The primary outcome 'adverse effect' is reported in tables 3 and 4.

mg; group III, trazodone $50 \mathrm{mg}$; and group IV, diazepam $15 \mathrm{mg}$. A comparison of the reported adverse effects for trazodone with diazepam revealed that diazepam was associated with more effects. The main effects reported were drowsiness, vertigo and cognitive impairment. In addition, the number of individuals in use of diazepam reporting adverse effects was also higher. No difference in

Table 3 Description of studies that reported the number of participants that experienced adverse effects and dropped out due to adverse effects $(n=4)$

\begin{tabular}{|c|c|c|c|}
\hline Authors (year) & Groups & $\begin{array}{l}\text { No of } \\
\text { participants } \\
\text { with adverse } \\
\text { effects/total } \\
(\%)\end{array}$ & $\begin{array}{l}\text { No of } \\
\text { participants } \\
\text { that } \\
\text { dropped } \\
\text { out }\end{array}$ \\
\hline \multirow[t]{2}{*}{$\begin{array}{l}\text { Studer et al } \\
2012^{29}\end{array}$} & $\begin{array}{l}\text { Midazolam } \\
7.5 \mathrm{mg}\end{array}$ & $6 / 12(50.0)$ & 0 \\
\hline & $\begin{array}{l}\text { Clonidine } 150 \\
\mu \mathrm{g}\end{array}$ & $5 / 12$ (41.6) & \\
\hline \multirow[t]{2}{*}{$\begin{array}{l}\text { Rodrigo and } \\
\text { Cheung }^{22} 1987\end{array}$} & $\begin{array}{l}\text { Midazolam } \\
15 \mathrm{mg}\end{array}$ & $17 / 30(56.6)$ & 0 \\
\hline & Placebo & $9 / 30(30.0)$ & \\
\hline \multirow[t]{2}{*}{$\begin{array}{l}\text { Manani et al } \\
1979^{21}\end{array}$} & $\begin{array}{l}\text { Trazodone } 25 \\
\text { mg }\end{array}$ & $12 / 20(60.0)$ & 0 \\
\hline & $\begin{array}{l}\text { Trazodone } 50 \\
\text { mg }\end{array}$ & 11/21 (52.3) & \\
\hline \multirow[t]{2}{*}{$\begin{array}{l}\text { Pinheiro et al } \\
2014^{30}\end{array}$} & $\begin{array}{l}\text { Valeriana } \\
\text { officinalis } 100 \\
\text { mg }\end{array}$ & 9/10 (90.0) & 0 \\
\hline & Placebo & $7 / 10(70.0)$ & \\
\hline
\end{tabular}

the heart rate and blood pressure was observed between the groups. ${ }^{21}$

An RCT with a crossover design (washout not reported) allocated 20 participants undergoing periodontal surgery to group I, diazepam 5 or $10 \mathrm{mg}$ (according to body weight), or group II, placebo, 1 hour before surgery. No significant differences in oxygen saturation were observed between the groups. ${ }^{26}$

\section{Midazolam (7.5 and $15 \mathrm{mg}$ )}

An RCT with a crossover design (washout of 30 days) allocated 12 patients undergoing bilateral surgical third molar extraction to receive the following interventions 1 hour before the procedure: group I, midazolam 7.5 $\mathrm{mg}$, and group II, clonidine $150 \mu \mathrm{g}$. The level of satisfaction with the treatment was determined using the Visual Analogue Scale with ratings ranging from 'no satisfaction' $(0 \%)$ to 'complete satisfaction' $(100 \%)$. Around $77 \%$ of the patients who received midazolam were satisfied compared with $75 \%$ of those given clonidine. There was no difference in the number of participants or adverse effects. No significant difference was observed in heart rate between the groups studied. ${ }^{29}$

Another RCT allocated 15 participants undergoing implant placement to receive either group I, midazolam $15 \mathrm{mg}$, or group 2, placebo 1 hour before the procedure. The use of midazolam proved ineffective as a premedication anxiolytic for preventing myocardial arrhythmias. ${ }^{24}$

An RCT with a crossover design allocated 30 patients undergoing bilateral surgical third molar extraction to group I, midazolam $15 \mathrm{mg}$ (single dose), or group II, placebo $45 \mathrm{~min}$ before the dental procedure. They reported a higher number of adverse effects with 
Table 4 Description of the adverse effects reported by the included studies $(n=5)$

\begin{tabular}{|c|c|c|c|c|}
\hline Author/year & $\begin{array}{l}\text { Intervention group } \\
\text { (number of } \mathrm{AE} \text { ) }\end{array}$ & $\begin{array}{l}\text { Description of the effects } \\
\text { (number of AE) }\end{array}$ & $\begin{array}{l}\text { Comparator group } \\
\text { (number of AE) }\end{array}$ & $\begin{array}{l}\text { Description of the effects } \\
\text { (number of AE) }\end{array}$ \\
\hline Dantas et $a l^{27}$ & $\begin{array}{l}\text { Midazolam } \\
15 \mathrm{mg}(54)\end{array}$ & $\begin{array}{l}\text { Drowsiness (33), muscular } \\
\text { relaxation (11), dizziness (7), } \\
\text { gastrointestinal problems (1), } \\
\text { amnesia (1), insomnia (1) }\end{array}$ & $\begin{array}{l}\text { Passiflora incarnate } \\
\text { L. (32) }\end{array}$ & $\begin{array}{l}\text { Drowsiness (20), muscular } \\
\text { relaxation (8), dizziness (2), } \\
\text { allergy (1), epistaxis (1) }\end{array}$ \\
\hline \multirow[t]{3}{*}{ Manani et $a l^{21}$} & $\begin{array}{l}\text { Diazepam } \\
15 \text { mg (36) }\end{array}$ & $\begin{array}{l}\text { Drowsiness (10), vertigo (3), } \\
\text { cognitive impairment (6) }\end{array}$ & $\begin{array}{l}\text { Trazodone } 50 \mathrm{mg} \\
(28)\end{array}$ & $\begin{array}{l}\text { Drowsiness (10), vertigo (5), } \\
\text { blurred vision (2), cognitive } \\
\text { impairment (11) }\end{array}$ \\
\hline & & & $\begin{array}{l}\text { Trazodone } 25 \mathrm{mg} \\
\text { (18) }\end{array}$ & $\begin{array}{l}\text { Drowsiness (15), vertigo (9), } \\
\text { blurred vision (6), cognitive } \\
\text { impairment (6) }\end{array}$ \\
\hline & & & Placebo (18) & $\begin{array}{l}\text { Drowsiness (12), vertigo (1), } \\
\text { blurred vision (2), cognitive } \\
\text { impairment (3) }\end{array}$ \\
\hline $\begin{array}{l}\text { Rodrigo, } \\
\text { Cheung }^{22}\end{array}$ & $\begin{array}{l}\text { Midazolam } \\
15 \mathrm{mg}(46)\end{array}$ & $\begin{array}{l}\text { Drowsiness (17), dizziness (8), } \\
\text { memory loss (3), excitability(5), } \\
\text { depression (5), nausea (5), vomiting } \\
\text { (2), headache (3) }\end{array}$ & Placebo (29) & $\begin{array}{l}\text { Drowsiness (9), dizziness (4), } \\
\text { memory loss and excitability } \\
(1) \text {, depression (1), blurred } \\
\text { vision (1), insomnia (5), } \\
\text { hallucinations (1), nausea (4), } \\
\text { vomiting (1), headache (2) }\end{array}$ \\
\hline Studer et $a l^{29}$ & $\begin{array}{l}\text { Midazolam } 7.5 \mathrm{mg} \\
\text { (6) }\end{array}$ & $\begin{array}{l}\text { Dizziness (3); nausea, headache } \\
\text { and fatigue (1); cognitive deficit (2) }\end{array}$ & $\begin{array}{l}\text { Clonidine } 0.15 \mathrm{mg} \\
(6)\end{array}$ & $\begin{array}{l}\text { Nausea (2), drowsiness (3), } \\
\text { fainting (1) }\end{array}$ \\
\hline
\end{tabular}

$\mathrm{AE}$, adverse effects.

midazolam compared with placebo, in particular drowsiness, dizziness and excitability. ${ }^{22}$

\section{Erythrina mulungu $500 \mathrm{mg}$}

The effectiveness of E. mulungu $500 \mathrm{mg}$ (single dose) was assessed in a crossover design RCT (washout period of 15 days) involving 30 patients undergoing bilateral extraction of impacted third molars compared with placebo. Both drugs were administered 1 hour before the dental procedure. Anxiety was determined based on Corah's DAS Scores. Volunteers with higher anxiety levels tended to prefer herbal medicine. The heart rate, systolic and diastolic blood pressure and oxygen saturation were not significantly different between the groups studied. ${ }^{28}$

\section{Passiflora incarnata L. $260 \mathrm{mg}$ and midazolam $15 \mathrm{mg}$}

An RCT with a crossover design allocated 40 participants undergoing mandibular third molar extraction into two groups (washout period of 15-30 days). Each group received interventions $30 \mathrm{~min}$ before the procedure: group I, $260 \mathrm{mg}$ of P. incarnata and midazolam $15 \mathrm{mg}$. Corah's DAS was used before and after the surgical procedure. Both drugs proved to be effective for controlling anxiety, although midazolam $15 \mathrm{mg}$ was more effective than herbal medicine. The most frequent adverse effects, particularly drowsiness and muscular relaxation, occurred with midazolam. The heart rate, systolic and diastolic blood pressure and oxygen saturation were not significantly different between the groups. ${ }^{27}$

\section{Valeriana officinalis $100 \mathrm{mg}$}

A crossover RCT (washout period of 15 days) allocated 20 participants undergoing bilateral third molar extraction into two groups that received the intervention 1 hour before the procedure: group I, V. officinalis $100 \mathrm{mg}$, and group II, placebo. Anxiety was measured using the DAS. Herbal medicine was more effective in controlling anxiety than a placebo. No differences were reported in the number of adverse effects, with the most common being drowsiness and muscular relaxation. Herbal medicine promoted less change in the heart rate and blood pressure compared with a placebo. ${ }^{30}$

\section{DISCUSSION}

Main findings and literature comparison

This review has evaluated the available evidence on the effectiveness and safety of oral sedation in adults undergoing dental procedures using 10 RCTs. The majority of the RCTs evaluated benzodiazepine class drugs for oral sedation, where the most commonly used was midazolam. Most of the studies were conducted in Brazil, none of which met all the evaluation criteria for risk of bias. The main methodological flaws were related to randomisation and allocation concealment.

The heterogeneity of the interventions and doses precluded a meta-analysis for all the outcomes assessed 
being performed. The primary outcomes reported by the studies were anxiety and the adverse effects. ${ }^{21-23} 25$ 27-30

In general, alprazolam $(0.5$ and $0.75 \mathrm{mg}),{ }^{23}$ midazolam $15 \mathrm{mg}$, P. incarnata $260 \mathrm{mg},{ }^{27}$ V. officinalis, ${ }^{30}$ and E. mulung $u^{28}$ were considered effective for controlling anxiety.

The results revealed a higher number of adverse effects associated with midazolam use, ${ }^{22} 27$ followed by diazepam. ${ }^{21}$ In addition, a greater number of patients reported adverse effects from these benzodiazepines. However, these findings should be interpreted with caution, given that the high number of reports might be related to the larger number of participants in these studies. Moreover, these findings are based on reports of only one study, where a lack of comparability between studies hampers any meaningful conclusion.

There was no difference in the number of patients that exhibited adverse effects after using midazolam $7.5 \mathrm{mg}$ and clonidine $150 \mu \mathrm{g},{ }^{29}$ but more adverse effects were reported in the group that received midazolam $15 \mathrm{mg}$ than in the placebo group. These results suggest that an increase in midazolam dose may be associated with a higher number of adverse effects.

No difference was found between midazolam $7.5 \mathrm{mg}$ and clonidine $150 \mu \mathrm{g}$ regarding satisfaction with the treatment. ${ }^{29}$ The physiological parameters showed no statistical difference by any intervention. No significant differences in the heart rate or blood pressure were evident when comparing E. mulungu to placebo, ${ }^{28} P$. incarnata to midazolam, ${ }^{27}$ midazolam to clonidine ${ }^{29}$ and diazepam to placebo or trazodone. ${ }^{21}$ However, the use of $V$. officinalis was associated with less change in these parameters relative to a placebo. ${ }^{30}$ There was no difference in oxygen saturation for the use of E. mulungu versus placebo, ${ }^{28} P$. incarnata versus midazolam ${ }^{27}$ or diazepam versus placebo. ${ }^{26}$

Although there are public policies aimed at herbal medicines in Brazil, such as the National Program for Medicinal Plants and Herbal Medicines (Decree Number 5813 of 2006), the use of herbal medicines is not common in dentistry. Three RCTs with herbal medicines were from Brazil; this is probably because oral sedation is a common practice in dental procedures compared with other countries that use intravenous and other routes for sedation.

Previous systematic reviews could not be compared with the present study's findings because the RCTs included in these reviews were not restricted to the oral route. ${ }^{10} 14$ Also, these reviews failed to report most of the outcomes assessed in the present study.

A previous systematic review assessed the safety of using sedation drugs by any administration route in patients undergoing dental procedures. Ten of the studies included were RCTs, but none of these were included in our study because they used a combination of drugs or other routes of administration. Midazolam was the most commonly used drug, irrespective of the administration route. Although the authors stated that the drug appeared to be safe for sedation, the risk of bias of the studies was not considered, and further clinical trials were suggested to confirm the findings. ${ }^{10}$

Another systematic review investigated the anxiolytic effect of midazolam in dental surgery, regardless of the administration route. ${ }^{14}$ Of the ten studies reviewed, three involved oral administration, of which only one RCT was included in the present study since the other clinical trials used a combination of different drugs or alternative routes of administration. ${ }^{29}$

In the literature, no secondary studies that compared outcomes to the treatment and physiological parameters were found.

\section{Study strengths and limitations}

This review was carried out with methodological rigour and evaluated the risk of bias, which has not been performed previously in similar reviews. ${ }^{10} 14$ The strengths of the present review include its explicit eligibility criteria, broad extensive database search and study selection by reviewers working both independently and in pairs.

The primary studies included are a limiting factor to the findings due to their methodological quality, the non-reporting of clinical outcomes and different comparator groups. This meant that a meta-analysis could not be conducted. Another notable factor was the heterogeneous method of reporting anxiety outcomes among studies.

It is also noteworthy that the vast majority of the RCTs $(90 \%)$ failed to consider the patient's anxiety level as a study inclusion criterion. Only one study reported that patients with higher anxiety levels tended to prefer herbal medicine. ${ }^{28}$ This information is important in that according to the literature, oral sedation can help most patients with mild to moderate levels of fear and anxiety but may be ineffective in patients with high levels of anxiety. $^{11} 31$

\section{Implications for clinical practice and research}

Our findings suggest that benzodiazepines and herbalbased medicines could be safely used for oral sedation in outpatient dental surgical procedures. Dental surgeons should devise surgical plans based on the patient's condition. This requires a detailed analysis in which the patient's level of anxiety and fear concerning the procedure is determined so that the most suitable medication can be administered.

None of the RCTs evaluated all of the outcomes proposed to determine the effectiveness and safety of oral sedation in dental surgical procedures. Also, a comparison between the studies was not possible due to the different drugs investigated. Therefore, further clinical trials adopting more methodological rigorous data collection and methodological guidelines should be conducted.

It is important to point out that although the findings of this review are somewhat limited, benzodiazepines and herbal-based medicines both appear to be safe under the conditions reported in the RCTs included (single dose administered orally). 
The present review synthesises the available evidence on the effectiveness and safety of oral sedation in adults undergoing dental surgical procedures. This can help guide the decision-making process in dental practice so as to reduce patient anxiety in clinical procedures.

\section{CONCLUSION}

The results suggest that the use of alprazolam, midazolam, P. incarnate, V. officinalis and E. mulungu is effective and safe in controlling anxiety among adult patients undergoing dental interventions. Midazolam was the most studied drug and was associated with the highest rate of adverse effects. However, given the study's limitations concerning the number of studies reviewed, different comparisons between the studies and incomplete outcome reporting, further clinical trials should be conducted to confirm the effectiveness and safety of these drugs.

\section{Twitter Luciane Cruz Lopes @lulopesbr}

Contributors JOA contributed as the principal investigator and led the writing of the manuscript. CCB, LCL and RHLM are the project managers and coinvestigators and contributed to the writing and revision of the manuscript. NKA, CCG and JCR are coinvestigators and contributed to the writing and revision of the manuscript. All authors have read and approved the final manuscript.

Funding The authors have not declared a specific grant for this research from any funding agency in the public, commercial or not-for-profit sectors.

Competing interests None declared.

Patient consent for publication Not required.

Provenance and peer review Not commissioned; externally peer reviewed.

Supplemental material This content has been supplied by the author(s). It has not been vetted by BMJ Publishing Group Limited (BMJ) and may not have been peer-reviewed. Any opinions or recommendations discussed are solely those of the author(s) and are not endorsed by BMJ. BMJ disclaims all liability and responsibility arising from any reliance placed on the content. Where the content includes any translated material, BMJ does not warrant the accuracy and reliability of the translations (including but not limited to local regulations, clinical guidelines, terminology, drug names and drug dosages), and is not responsible for any error and/or omissions arising from translation and adaptation or otherwise.

Open access This is an open access article distributed in accordance with the Creative Commons Attribution Non Commercial (CC BY-NC 4.0) license, which permits others to distribute, remix, adapt, build upon this work non-commercially, and license their derivative works on different terms, provided the original work is properly cited, appropriate credit is given, any changes made indicated, and the use is non-commercial. See: http://creativecommons.org/licenses/by-nc/4.0/.

\section{ORCID IDs}

Cristiane de Cássia Bergamaschi http://orcid.org/0000-0002-6608-1806

Luciane Cruz Lopes http://orcid.org/0000-0002-3684-3275

Caio Chaves Guimarães http://orcid.org/0000-0002-1672-528X

Rogério Heládio Lopes Motta http://orcid.org/0000-0002-6983-7883

\section{REFERENCES}

1 Kapur A, Kapur V. Conscious sedation in dentistry. Ann Maxillofac Surg 2018;8:320-3.

2 Fiorillo L. Conscious sedation in dentistry. Medicina 2019;55:778.

3 Dundee Dental Education Centre. Scottish dental clinical effectiveness programme: conscious sedation in dentistry. Frankland Building, 2012: 1-37.

4 Academy of Medical Royal Colleges. Safe sedation practice for health care procedures. London, 2013.
5 The Dental Faculties of the Royal Colleges of Surgeons and the Royal College of Anaesthetists. Standards for conscious sedation in the provision of dental care, 2015.

6 National Dental Advisory Committee. Scottish government. emergency drugs and equipment in primary dental care, 2015.

7 Coulthard P, Bridgman CM, Gough L, et al. Estimating the need for dental sedation. 1. The Indicator of Sedation Need (IOSN) - a novel assessment tool. Br Dent J 2011;211:E10.

8 Haas DA. Oral sedation in dental practice. Royal College of dental surgeons of Ontario, 2015.

9 Coulthard P. Conscious sedation guidance. Evid Based Dent 2006;7:90-1.

10 Corcuera-Flores J-R, Silvestre-Rangil J, Cutando-Soriano A, et al. Current methods of sedation in dental patients - a systematic review of the literature. Med Oral Patol Oral Cir Bucal 2016;21:579-86.

11 Donaldson M, Gizzarelli G, Chanpong B. Oral sedation: a primer on anxiolysis for the adult patient. Anesth Prog 2007;54:118-29.

12 Lino PA, Martins MAP, Silva MEdeSE, et al. Anxiolytics, sedatives, and hypnotics prescribed by dentists in Brazil in 2010. Biomed Res Int 2017;2017:1-5.

13 Dionne RA, Yagiela JA, Coté CJ, et al. Balancing efficacy and safety in the use of oral sedation in dental outpatients. J Am Dent Assoc 2006;137:502-13.

14 Chen Q, Wang L, Ge L, et al. The anxiolytic effect of midazolam in third molar extraction: a systematic review. PLoS One 2015; 10:e0121410.

15 Araújo JdeO, Motta RHL, Bergamaschi CdeC, et al. Effectiveness and safety of oral sedation in adult patients undergoing dental procedures: protocol for a systematic review. BMJ Open 2018;8:e017681.

16 Altman R, Alarcón G, Appelrouth D, et al. The American College of rheumatology criteria for the classification and reporting of osteoarthritis of the hand. Arthritis Rheum 1990;33:1601-10.

17 Higgins JPT, Green S. Cochrane Handbook for systematic reviews of interventions version 5.1.0: the Cochrane collaboration, 2011.

18 Akl EA, Sun X, Busse JW, et al. Specific Instructions for estimating unclearly reported blinding status in randomized trials were reliable and valid. J Clin Epidemiol 2012;65:262-7.

19 Guyatt GH, Oxman AD, Kunz R, et al. GRADE guidelines: 7. Rating the quality of evidence--inconsistency. J Clin Epidemiol 2011;64:1294-302.

20 Guyatt GH, Oxman AD, Montori V, et al. GRADE guidelines: 5 . Rating the quality of evidence--publication bias. J Clin Epidemiol $2011 \mathrm{~b} ; ; 64: 1277-82$. Dec.

21 Manani G, Paniz P, Beltrame A, et al. [Double-blind analysis of the possibilities of the use of trazodone in sedation of ambulatory dental patients]. Minerva Stomatol 1979;28:193-200.

22 Rodrigo MR, Cheung LK. Oral midazolam sedation in third molar surgery. Int J Oral Maxillofac Surg 1987;16:333-7.

23 Coldwell SE, Milgrom P, Getz T, et al. Amnestic and anxiolytic effects of alprazolam in oral surgery patients. J Oral Maxillofac Surg 1997;55:1061-70.

24 Romano MM, Soares MS, Pastore CA, et al. A study of effectiveness of midazolam sedation for prevention of myocardial arrhythmias in endosseous implant placement. Clin Oral Implants Res 2012;23:489-95.

25 Branco P, Bassualdo A. Estudo clínico duplo-cedo randomizado controlado POR placebo sobre O uso pré-operatório de ansiolítico em implantodontia. Implant News 2012;9:40-7.

26 Shivananda H, Raghava KV, Sudhakar SK, et al. Comparative evaluation of oxygen saturation during periodontal surgery with or without oral conscious sedation in anxious patients. J Indian Soc Periodontol 2014;18:718-22.

27 Dantas L-P, de Oliveira-Ribeiro A, de Almeida-Souza L-M, et al. Effects of Passiflora incarnata and midazolam for control of anxiety in patients undergoing dental extraction. Med Oral Patol Oral Cir Bucal 2017:22:95-101.

28 Silveira-Souto ML, São-Mateus CR, de Almeida-Souza LM, et al. Effect of Erythrinamu lungu on anxiety during extraction of third molars. Med Oral Patol Oral Cir Bucal 2014;19:e518-24.

29 Studer FR, Grätz KW, Mutzbauer TS. Comparison of clonidine and midazolam as anxiolytic premedication before wisdom tooth surgery: a randomized, double-blind, crossover pilot study. Oral Maxillofac Surg 2012;16:341-7.

30 Pinheiro MLP, Alcântara CEP, de Moraes M, et al. Valeriana officinalis L. for conscious sedation of patients submitted to impacted lower third molar surgery: a randomized, double-blind, placebo-controlled split-mouth study. J Pharm Bioallied Sci 2014;6:109-14.

31 Gallagher C. Benzodiazepines: sedation and agitation. Dent Update 2016;43:83-9. 